\title{
Investigating the kinetics at low temperature heat pump drying and conventional drying of osmotic dehydrated blueberries
}

\author{
Hristo Hristov ${ }^{1 *}$, Svetoslav Aleksandrov ${ }^{2}$, Todorka Petrova ${ }^{2}$, Milena Ruskova ${ }^{2}$, \\ Velitchka Gotcheva ${ }^{3}$, and Nikolay Penov ${ }^{4}$ \\ ${ }^{1}$ Department of Machines and apparatuses for food industry ${ }^{1}$, University of food technologies, \\ Plovdiv, Bulgaria \\ ${ }^{2}$ Institute of food preservation and quality, Plovdiv, Bulgaria \\ ${ }^{3}$ Department of Biotechnology, University of food technologies, Plovdiv, Bulgaria \\ ${ }^{4}$ Department of Food preservation and refrigeration technology, University of food technologies, \\ Plovdiv, Bulgaria
}

\begin{abstract}
The possibilities for low-temperature heat pump and conventional drying of blueberries during preliminary osmotic dehydration was studied. A full factor experiment of type $2^{2}+3$ was performed. The kinetics of the process during variation of the main mode parameters: inlet temperature and thickness of the drying layer (load on the scaffolding) was studied. The curves of the drying process $U=f(\tau)$ and the curves of the drying speed $d U / d \tau=f(U)$ were constructed. The influence of the regime parameters on the drying time was established. Regression models of the drying coefficient during the second period of drying were presented.
\end{abstract}

\section{Introduction}

The fruits of the blueberry family (Vacciniaceae) which in Bulgaria are presented by bilberry ( V. myrtillus $L)$, blueberry (V. uliginosum), cranberry (V. Vitis - idaea) and Caucasian bilberry (V. Arctostaphylos). Their dry substance content varies in the range from 12 to $18 \%$. Depending on the type and degrees of maturity, the amount of carbohydrates in blueberries is about $15 \%$, of which reducing sugars predominate (about $10 \%$ ), and the fiber content can reach $0,9 \%$. The detected concentration of total organic acids is from 0,5 to $1,7 \mathrm{mg} / 100 \mathrm{~g}$. Polyunsaturated fats $(0,15 \mathrm{~g} / 100 \mathrm{~g})$ predominate. The ash content of blueberries varies from 0,19 to $0,24 \%[1]$.

Blueberries are a source of biologically active substances, such as phenolic compounds, tannins, stilbenes, flavonoids, anthocyanins, vitamin A and calcium, which have a positive effect on human health and have protective properties against diseases such as memory loss, cancer, heart disease, urinary tract infections, impaired vision and cell aging [2].

\footnotetext{
*corresponding author: h_geo@mail.bg
} 
About 90 percent of the world's blueberry production is in North America, with more than 42000 tons produced annually, according to the United Nations Food and Agricultural Organization.

About $50 \%$ of all blueberries produced are available on the market fresh, with a shelf life of 2 to 3 weeks. Based on research and implemented industrial practices, drying and osmotic dehydration have been found to be effective ways to ensure the consumption of blueberries out of season [3]. When using osmotic dehydration, a large part of the water is released without causing changes in the phases, including a cost-effective ingredient (sugar) in an expensive fruit, which increases the weight of the product.

Various methods have been used to preserve freshly and osmotically dehydrated blueberries to a state of stable low moisture content.

The drying of fresh, frozen or osmotically dried blueberries has been studied, but nevertheless the main task before preserving these fruits is to determine technological solutions, through which to preserve the most heat-sensitive biologically active substances and the color of the final product [4].

The main goal of the present investigation is to study the drying kinetics of low temperature heat pump and conventional drying of osmotically dehydrated blueberries.

\section{MATERIALS AND METHODS}

\subsection{Materials}

Pre-osmotically dehydrated blueberries were used.

\subsection{Methods}

\subsubsection{Determination of dry substance content}

A weighting method was used to determine the dry substance content.

\subsubsection{Investigation of drying kinetics of pre-osmotically dehydrated blueberries}

The curve of drying process is constructed $-\mathrm{U}_{\mathrm{c}}=\mathrm{f}(\tau)$, after which the drying speed curve is derived from it $-\frac{d U^{c}}{d \tau}=\mathrm{f}\left(\mathrm{U}_{\mathrm{c}}\right)$ and $\ln \left(U^{c}-U_{p}^{c}\right)=f(\tau)$ [5], where: $\mathrm{U}$-moisture content, $\mathrm{kg}$ $\mathrm{H}_{2} \mathrm{O} / \mathrm{kg}$ dry substance; $\tau$ - drying time, min.

The speed coefficient of the drying process is determined by the equation of the drying process curve:

$$
-\frac{d U^{c}}{d \tau}=K_{c}\left(U^{c}-U_{p}^{c}\right),
$$

$U_{p}^{c}$ - equilibrium moisture content, $\%$;

$U^{c}$ - current moisture content, \%;

$\mathrm{K}_{\mathrm{c}}$ - speed coefficient of the drying process, $\mathrm{min}^{-1}$.

\subsubsection{Planning of experiment}

A full factorial experiment (ANOVA) of the type $2^{2}$ with three replicates in the center of experiment was used. The response surface method was applied to determine the influence of the independent variables $[6,7]$. 


\section{Results and discussion}

\subsection{Matrix for conducting the experiment and results of the conducted researches}

After preliminary studies, the main independent variables influencing the kinetics of the drying process are determined:

- The temperature of the drying agent $-\mathrm{t},{ }^{\circ} \mathrm{C}$;

- Thickness of the drying layer (load on the scaffolding) $-\sigma, \mathrm{kg} / \mathrm{m}^{2}$.

The levels of variation of the independent variables for the two types of drying are presented in table 1.

Table 1. Variation levels and names of the independent variables in heat pump and conventional drying of osmotically dehydrated blueberries

\begin{tabular}{|l|c|c|c|c|}
\hline & \multicolumn{2}{|c|}{ heat pump } & \multicolumn{2}{c|}{ conventional } \\
\hline Variables & $\mathrm{t},{ }^{0} \mathrm{C}$ & $\sigma, \mathrm{kg} / \mathrm{m}^{2}$ & $\mathrm{t},{ }^{0} \mathrm{C}$ & $\sigma, \mathrm{kg} / \mathrm{m}^{2}$ \\
\hline High level, $\mathrm{z}_{\mathrm{j}}{ }^{\mathrm{h}}\left(\mathrm{x}_{\mathrm{i}}{ }^{\mathrm{h}}\right)$ & 50 & 15 & 70 & 15 \\
\hline Low level, $\mathrm{z}_{\mathrm{i}}^{\mathrm{h}}\left(\mathrm{x}_{\mathrm{i}}{ }^{\mathrm{l}}\right)$ & 40 & 5 & 50 & 5 \\
\hline Center of the plan, $\mathrm{z}_{\mathrm{j}}{ }^{\mathrm{o}}\left(\mathrm{x}_{\mathrm{j}}{ }^{\mathrm{o}}\right)$ & 45 & 10 & 60 & 10 \\
\hline Interval of variation, $\Delta \mathrm{z}_{\mathrm{j}}$ & 5 & 5 & 10 & 5 \\
\hline
\end{tabular}

Table 2. Plan of the experiment (Anova $2^{2}+3$ )

\begin{tabular}{|c|c|c|c|c|c|c|}
\hline \multicolumn{3}{|c|}{ Drying } & \multicolumn{2}{c|}{ Heat pump } & \multicolumn{2}{c|}{ Conventional } \\
\hline \multirow{2}{*}{$№$} & $\mathrm{X}_{1}\left(\mathrm{t},{ }^{0} \mathrm{C}\right)$ & $\mathrm{X}_{2}\left(\sigma, \mathrm{kg} / \mathrm{m}^{2}\right)$ & $\mathrm{t},{ }^{0} \mathrm{C}$ & $\sigma, \mathrm{kg} / \mathrm{m}^{2}$ & $\mathrm{t},{ }^{0} \mathrm{C}$ & $\sigma, \mathrm{kg} / \mathrm{m}^{2}$ \\
\cline { 2 - 7 } & \multicolumn{2}{|c|}{ coded } & \multicolumn{2}{c|}{ natural } & \multicolumn{2}{c|}{ natural } \\
\hline 1. & - & - & 40 & 5 & 50 & 5 \\
\hline 2. & + & - & 50 & 5 & 70 & 5 \\
\hline 3. & - & + & 40 & 15 & 50 & 15 \\
\hline 4. & + & + & 50 & 15 & 70 & 15 \\
\hline 5. & 0 & 0 & 45 & 10 & 60 & 10 \\
\hline 6. & 0 & 0 & 45 & 10 & 60 & 10 \\
\hline 7. & 0 & 0 & 45 & 10 & 60 & 10 \\
\hline
\end{tabular}

\subsection{Kinetics of the drying process of osmotically dehydrated blueberries under different technological regimes of drying}

Figures $1 \mathrm{a}$ and $\mathrm{b}$ show the drying curves $-\mathrm{U}=\mathrm{f}(\tau)$ in two methods - low temperature heat pump and conventional drying of osmotically dehydrated blueberries. Depending on the temperature of the drying agent and the load on the scaffolding, the time for conventional drying varies from 8 to 15 hours, and for low-temperature heat pump drying from 4 to 6 hours. It is noteworthy that the time to reach equilibrium humidity in conventional drying is about twice as long as the heat pump.

When analyzing the graphs, the absence of the first period (period of constant drying speed) is noticed. For all curves obtained, a period of reduction of the drying speed is 
reported. The nature of the drying curves during this period depends on the composition, structure and size of the product, as well as on the form of binding of the water in it.

Figures $2 \mathrm{a}$ and $\mathrm{b}$ show the drying rate curves $\left(\frac{d U^{c}}{d \tau}=\mathrm{f}\left(\mathrm{U}_{\mathrm{c}}\right)\right)$ by two methods - low temperature heat pump and conventional drying of osmotically dehydrated blueberries. They express the drying speed as a function of the moisture content of the product. Analysis of the drying speed curves shows that the above mentioned trends are observed. Impressive are the lack of a period of constant drying speed and the presence of a period of decreasing drying speed. The experimentally obtained results for heat and mass transfer, presented by drying speed curves, are comparable to those of [8] in convective drying of osmotically dehydrated pieces of papaya.

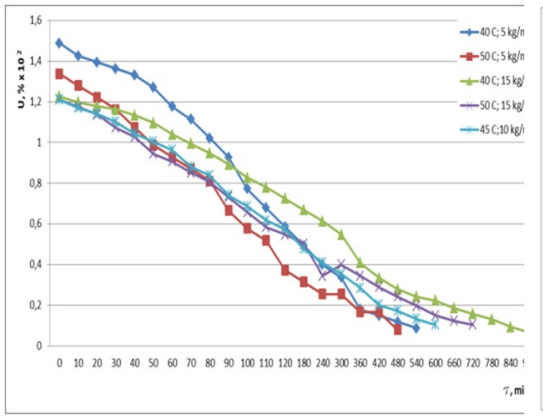

a) conventional drying

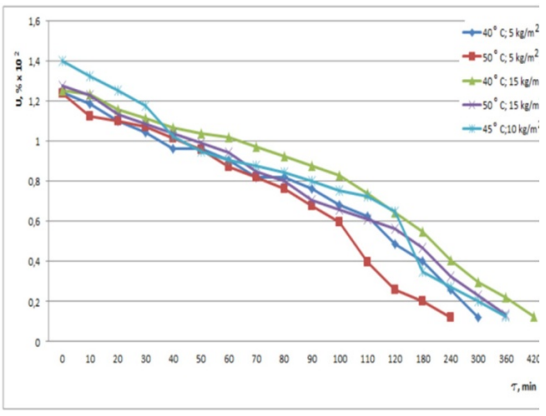

b) heat pump drying

Fig. 1. Drying curves of osmotically dehydrated blueberries

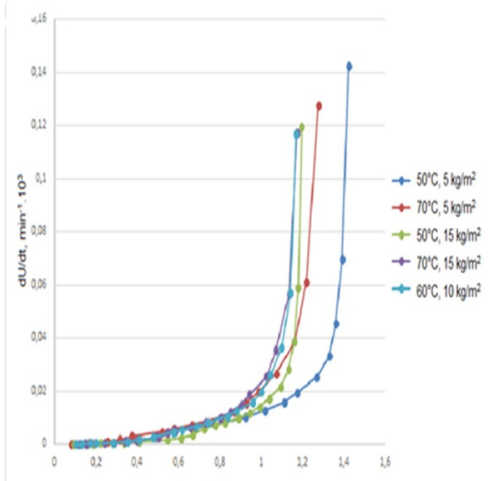

a) conventional drying

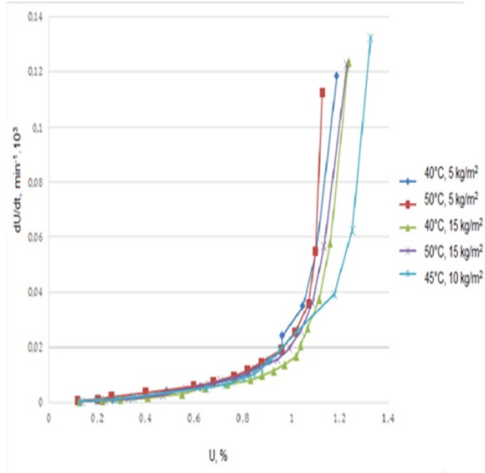

b) heat pump drying

Fig. 2 Drying curves of osmotic dehydrated blueberries

In figures $2 a$ and $b$, the presence of a second critical point can be established in all variants of the experiment. This is characteristic of this part of the curves in capillary-porous colloidal bodies. In this case, two sub periods stand out: a sub period of uniform decelaration and a sub period of non-uniform deceleration. They can be used to judge the nature of evaporation of the bound water in material. The explanation for this fact can be found in the complex nature of the structure of the solid skeleton of the product, the ratio of different forms of bound moisture, the mechanism of its transfer, as well as the pretreatment of the 
product (osmotic dehydration). Figure 3 show the response surfaces of the obtained regression equations of the speed drying coefficients.

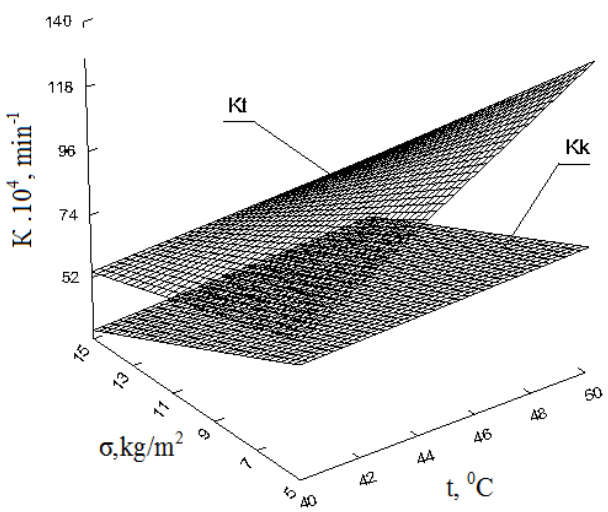

Fig. 3. Speed drying coefficients

$$
\begin{array}{ll}
\text { Kt. } 104=-255.6+8.6 * \mathrm{t}+18.5 * \sigma-0.52 * \mathrm{t} * \sigma, \min ^{-1} & \mathrm{R} 2=97 \% \\
\text { Kk. } 104=71.0+0.4 * \mathrm{t}-4.4 * \sigma+0.02 * \mathrm{t}^{*} \sigma \quad, \min ^{-1} & \mathrm{R} 2=94 \%
\end{array}
$$

In both drying methods, the maximum values of the drying coefficients are obtained at variant №2 (table 2). The maximum value for heat pump drying $\mathrm{K}_{\mathrm{t}}=0,138, \mathrm{~min}^{-1}$ is about twice as high as the convective speed drying coefficient $\mathrm{K}_{\mathrm{k}}=0,075$, $\mathrm{min}^{-1}$.

\section{Conclusion}

A combined drying method with pre-osmotic treatment is applied, as a result of which the free moisture is released. As a result of the osmotic treatment dried blueberries in both methods have an increased sugar content. This allows the dried blueberries to have a higher moisture content with a water activity lower than 0,6 . This guaranties the safety of the final product, as well as its better organoleptic properties. The time to reach equilibrium humidity in conventional drying of osmotically dehydrated blueberries is about twice as long ( 8 to 15 hours) compared to the heat pump drying ( 4 to 6 hours). Absence of a constant drying speed and presence of a period of decreasing drying speed was reported. A second critical point was also found during this second drying period, and two sub periods were reported: a sub period of uniform deceleration and a sub period of non-uniform deceleration.

\section{References}

1. K. Skupień, J. Oszmiański, J. Agricultural and Food Science, 16 (1), 46-55 (2007)

2. X. Wu, L. Gu, L. Prior, S. McKay. Journal of Agricultural and Food Chemistry, 52 (26), 7846-7856 (2004)

3. J. Shi, Z. Pan, T. McHugh, D. Wood, E. Hischberg, D. Olsonc. Food Science and Technology, 41 (10), 1962-1967 (2008) 
4. G. Skrede, E. Wrolsta, R. Durst. Journal of Food Science, 65 (2), 357-364 (2000)

5. K. Kolarov, Processes and apparatus in Food processing industry, Plovdiv, Publishing house Hr. Danov, 429-432 (1985) (In Bulgarian)

6. B. Bozhanov, I. Vutchkov, Statistical methods for modelling and optimization of multifactor objects, P.H Technika, Sofia, 1983 (in Bulgarian)

7. A. Lambrev, Basics of engineering experiment in terms of study of machines and apparatus in food industry, 1994 (in Bulgarian)

8. K. Park, A. Bin, F. Brod. Journal of Food Engineering, 56, 97-103 (2002) 